\title{
PENGEMBANGAN INSTRUMEN CABANG OLAHRAGA ATLETIK NOMOR TOLAK PELURU GAYA O'BRIEN PADA ATLET PUTRA PPLM PROVINSI RIAU
}

\author{
Ni Putu Nita Wijayanti, Slamet, Agus Wiranata \\ Fakultas Keguruan dan IImu Pendidikan Universitas Riau \\ nitawijayanti987@yahoo.com, slamet@gmail.com
}

\begin{abstract}
The problem in this reserch originated from the observation to the field researchers who focus on the implementation of the recruitment of athletes PPLM Riau province, especially athletics shot put the number of instrument test is still common for a number in athletics. Based on the needs analysis, the researchers designed a development instrument of shot-put from physical, technical, tactical, and mental aspect. Research and development of the instrument using a qualitative approach and method development research Research \& Development $(R \& D)$. The subjects in this research were four people who are all athletes PPLM Riau Province in 2016. Validity of test results using the product moment correlation can be described item development instruments, which have very high criteria consists of 4 items (36.36\%) are weight, height, push-ups and standing, while 7 other test items have value product moment correlation with high criteria as much as $63.36 \%$. For the results of reliability test $r 11=0.72$ This means that the reliability of the instrument development that researchers in the category of sufficient reliability.
\end{abstract}

Keywords: Development, Instrument, Shot Put.

\section{PENDAHULUAN}

Tolak peluru merupakan salah satu nomor lempar, dimana menurut Dragan (1979) dalam Siswantoyo (2009: 63) mengidentifikasi unsur/kriteria yang dibutuhkan antara lain tinggi badan dan berotot, anaerobic tinggi, power, ukuran biacromial sebaiknya tinggi, waktu reaksi, konsentrasi. untuk menolak diperlukan tenaga yang besar, ini berarti sang atlit yang berpostur tinggi dan besar akan mempunyai peluang lebih besar

\footnotetext{
Ni Putu Nita Wijayanti, Penerapan Model Pembelajaran Kooperatif Tipe Talking Stick Dapat Meningkatkan Hasil Belajar IPS Siswa Kelas Vb SDIT Insan Utama Pekanbaru
} 
untuk menjadi juara. Disamping kekuatan juga terdapat unsur lain yaitu kemampuan unsur ketangkasan, ketepatan waktu dan kecepatan melempar (Giri Wiarto, 2013: 57). Untuk memperoleh tolakan yang jauh, dapat melakukan latihan beban secara kontinyu dan dengan intensitas latihan yang tepat. Komponen kondisi fisik yang dominan dibutuhkan pada nomor tolak peluru antara lain: kekuatan, daya ledak, kecepatan, kelentukan, kelincahan dan keseimbangan (jurnalristanso.blogspot.com, 2014). Prestasi tolak peluru ditentukan oleh tiga faktor yaitu: ketinggian saat melepaskan, kecepatan saat melepaskan, dan sudut yang dibentuk saat melepaskan peluru. Untuk memiliki ketinggian saat melepaskan peluru diperlukan tinggi badan yang lebih, karena dengan memiliki ketinggian saat melepaskan peluru diperlukan tinggi badan yang lebih tinggi maka akan mempunyai ketinggian saat melepaskan peluru lebih tinggi. Untuk menghasilkan kecepatan saat melepaskan dibutuhkan tenaga yang besar yang secara normal apabila seseorang memiliki badan yang lebih besar akan memiliki tenaga yang lebih besar sehingga untuk menghasilkan kecepatan saat melepaskan peluru lebih cepat, dan sudut saat lepas sesuai dengan rumus kecepatan saat mengudara sangat besar (Iman Imanudin, Jurnal Upi, Vol. 3, 2011).

Pusat Pembinaan dan Latihan Olahraga Mahasiswa (PPLM) terbentuk dilandasi oleh keinginan yang kuat agar para atlet mahasiswa dapat meniti puncak prestasi olahraga di Indonesia, maka perlu dibentuk wadah pembinaan yaitu yang pada saat ini dikelola oleh Perguruan Tinggi dengan pengawasan dan dukungan anggaran berasal dari Kantor Kementerian Pemuda dan Olahraga dan Direktorat Jenderal Pendidikan Tinggi - Kementerian Pendidikan Nasional. Dibentuknya PPLM didasari adanya kesenjangan dan putusnya jenjang pembinaan olahraga Pusat Pembinaan dan Latihan Olahraga Pelajar (PPLP), dimana setelah atlet 
pelajar dibina pada wadah pembinaan olahraga pelajar tidak ada wadah yang dapat merefleksikan pembinaan olahraga dikalangan mahasiswa. Prestasi pada kalangan pelajar yang dicapai dianggap belum optimal, sedangkan atlet usia mahasiswa sudah seharusnya berprestasi internasional, minimal prestasi nasional karena pada usia tersebut sebagai usia emas atau "Golden Age".

Terbentuknya PPLM dimulai pada tahun 2003, sampai tahun 2011 telah ada 29 PPLM yang tersebar di 26 provinsi. Pada awalnya PPLM hanya membina cabang olahraga atletik saja, pada tahun 2007 mulai diupayakan penambahan cabang olahraga yang dibina, dengan mempertimbangkan atas efisien dan efektivitas serta mempertimbangkan potensi olahraga daerah. Seiring perkembangan jumlah PPLM maupun cabang olahraga yang dibina tersebut, perlu adanya Standar Pelayanan Minimal (SPM) tentang pengelolaan PPLM agar dapat dipakai sebagai acuan dalam penyelenggaraan dan pelaksanaannya, sehingga mampu mempercepat proses pencapaian prestasi.

PPLM Cabang olahraga atletik merupakan cabang olahraga yang paling banyak dimiliki oleh provinsi di Indonesia, dan nomor tolak peluru salah satu yang banyak dibina didalamnya. Data terbaru menginformasikan Atlet Indonesia atas nama Eki Febri Ekawati hanya mampu merebut medali perak nomor tolak peluru cabang atletik pesta olahraga negara Islam, "Islamic Solidarity Gamas di Stadion Atletik Jakabaring Palembang, Kamis malam. Atlet tolak peluru Indonesia itu kalah bersaing dengan, Leyla Rajabi dari Iran karena tolakannya hanya mencapai 14,00 meter. Sementara atlet Iran mampu mencatat prestasi dengan tolakan mencapai 17,02 meter sehingga mendapat medali emas dalam pesta olahraga Internasional tersebut. Dari data tersebut dapat terlihat perbandingan prestasi atlet antara juara 1 dan 2 terpaut 3 meter, 
dan untuk nomor tolak peluru perbedaannya sangat signifikan. Eki Febri bisa dikatakan parameter perkembangan tolak peluru di Indonesia karena dia juga merupakan juara 1 PON 2012 Riau dengan prestasi tolakan 13.85 meter. Melihat prestasi yang terpaut jauh dengan negara lain, maka perlu dilakukan evaluasi secara menyeluruh dengan menggunakan pendekatan Ilmu Pengetahuan dan Teknologi (IPTEK) olahraga.

Berdasarkan observasi di PPLM Provinsi Riau dan pengalaman peneliti sebagai atlet PPLM dari tahun 2005-2009 ada beberapa hal yang perlu mendapat perhatian khususnya saat perekrutan antara lain: perekrutan atlet belum menggunakan instrumen yang valid dan reliabel, tolak ukur rekruitmen atlet biasanya hanya mengandalkan parametrik hasil tolakan artinya belum memasukkan aspek pencapaian prestasi seperti fisik yang dominan, taktik dan mental, tolak ukur degradasi atlet seharusnya mengevaluasi seluruh komponen dalam PPLM itu sendiri misalnya manajemen kepengurusan, komponen latihan, pelatih, gizi, dan lain sebagainya. Pada penelitian ini masalah akan difokuskan pada rancangan bentuk instrument tes untuk rekruitmen atlet PPLM Provinsi Riau Cabang Olahraga Atletik nomor tolak peluru dari segi fisik, teknik, taktik dan mental.

Dalam nomor tolak peluru ada berbagai gaya tolakan diantaranya gaya O'Brein dan rotasi atau memutar seperti teknik gaya lempar cakram. Menurut James. Hay (1936 : 480,482) : O'Brein back-facing style of shotputting (Gaya O'Brein membelakangi arah tolak peluru). The rotational shot-putting of style of Aleksandr Barishnikov (U.S.S.R) (Gaya putaran (rotasi) dalam tolak peluru oleh Aleksandr Barishnikov). Daya ledak otot tungkai sangat diperlukan dalam pergeseran gaya O'Brein ini, hal ini komponen kondisi fisik yang menyangkut kemampuan seorang atlet (tolak peluru). Kekuatan dan kecepatan atau daya ledak otot pada dasarnya 
adalah kemampuan otot atau sekelompok otot tungkai untuk melakukan kerja tertentu, dalam hal ini yaitu dalam melakukan gerakan cabang olahraga tolak peluru. Dengan power otot lengan dan otot tungkai yang besar seorang penolak peluru dapat mencapai jarak yang maksimal, karena rangkaian gerak tolak peluru dimulai dari kaki sampai pergelangan tangan.

Salah satu komponen kondisi fisik (tubuh) yang sangat penting bagi atlet tolak peluru adalah power otot lengan. Pernyataan ini dapat diinterpretasikan bahwa dengan lengan yang baik tentunya memiliki potensi power yang dahsyat, begitu juga dengan seseorang yang memiliki power otot tungkai yang kuat maka akan bersinergi untuk dapat memaksimalkan tolakan seseorang. Namun hal itu tidak dapat terjadi dengan sendirinya, tetapi dihasilkan melalui letakan yang sitematik dan metodik yang cepat.

Sebagaimana penulis lihat pelaksanaan dari gerakan tolak peluru khususnya gaya O'Brein mahasiswa Pendidikan Olahraga UR, masih banyak terdapat kekurangan, dalam melakukan awalan, meluncur, menolak dan gerak lanjutannya sehingga tolakannya menjadi tidak maksimal. Oleh karena itu penulis ingin meneliti tentang power lengan dan tungkai sebagai 2 komponen yang sangat besar andilnya terhadap hasil tolak peluru gaya O'Brein pada mahasiswa Pendidikan Olahraga UR.

Tolak peluru merupakan salah satu nomor lempar yang diperlombakan dalam cabang olahraga atletik, dimana tujuan utama dari pelaksanaan tolak peluru, yaitu agar seorang petolak peluru mampu menolakan peluru sejauh-jauhnya yang sesuai dengan peraturan perlombaan yang berlaku. 
Tolak peluru memilik karakteristik yang sangat kompleks. Untuk mendapatkan hasil tolakan yang jauh Seorang atlet tolak peluru harus memiliki kekuatan, kecepatan dan teknik yang benar yang mencakup, jangkauan (Height of release), sudut lemparan (angle of release), kecepatan lemparan (speed of release). Menurut James Hay (1936:476) beberapa faktor dasar yang mempengaruhi hasil tolakan peluru yang maksimal, diantaranya adalah:

a. (Height of release) pelepasan tertinggi yang didukung oleh fisik.

b. (Speed of release) kecepatan melapaskan peluru (tolakan) didukung menggunakan didukung oleh kekuatan untuk memperoleh jarak yang maksimum.

c. (Angle of release) proses sudut pelepasan peluru didukung dengan kekuatan untuk memperoleh jarak yang maksimum.

d. Aerodynamic factor (faktor yang berkorelasi dengan ilmu dinamika udara seperti: kecepatan angin, oleh penempatan sudut tolakan yang benar, kecepatan gerakan/teknik.

Teknik tolak peluru gaya O'Brein menurut IAAF (1993:87) meliputi: persiapan (preparation), meluncur ke belakang (glide), menolak (delivery) dan pemulihan (recovery). Seperti gambar di bawah ini 


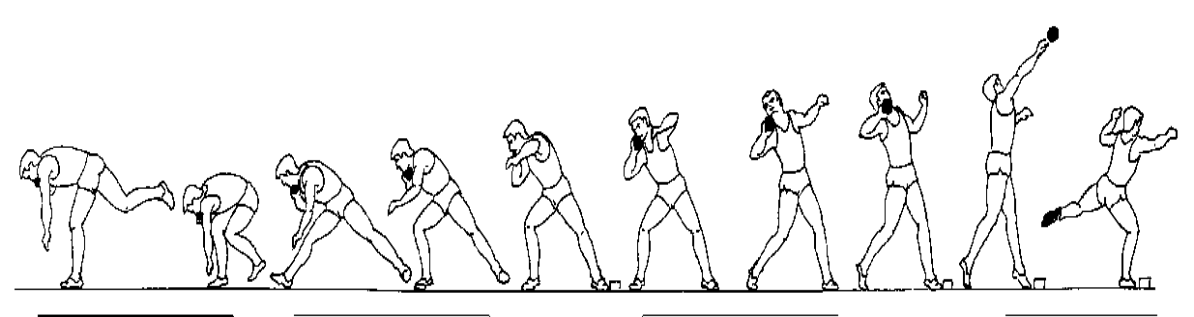

$\uparrow$ PREPARATION $\rightarrow$ GLIDE $\rightarrow 4$ DELIVERY $\longrightarrow \overline{\text { RECOVERY }}$

Gambar 1. Gerak Keseluruhan Gaya O’Brein

Sumber : IAAF Run Jump Throw (2000: 168)

\section{METODE PENELITIAN}

Penelitian Pengembangan Instrumen Cabang Olahraga Atletik Nomor Tolak Peluru PPLM Provinsi Riau ini merupakan suatu proses yang digunakan untuk mengembangkan dan memvalidasi produk Instrumen tolak peluru. Penelitian dan pengembangan instrumen ini menggunakan pendekatan kualitatif serta menggunakan metode Penelitian pengembangan Research \& Development ( $R$ \& D) yang terdiri dari sepuluh langkah antara lain (Sugiyono, 2008:407): (a) Melakukan penelitian dan pengumpulan informasi (kajian pustaka, pengamatan subyek, persiapan laporan pokok persoalan), (b)Melakukan perencanaan (pendefinisian keterampilan, perumusan tujuan, penentuan urutan pengajaran, dan uji coba skala kecil), (c) Mengembangkan bentuk produk awal (penyiapan materi pengajaran, penyusunan buku pegangan, dan perlengkapan evaluasi), (d) Melakukan uji lapangan permulaan (menggunakan 6-12 subyek), (e) Melakukan revisi terhadap produk utama (sesuai dengan saran-saran dari hasil uji lapangan permulaan), (f) Melakukan uji lapangan utama (dengan 30-100 subyek), (g) Melakukan revisi produk (berdasarkan saran-saran dan hasil uji coba lapangan utama), (h) Uji lapangan dengan 30-200 subyek, (i)Revisi produk akhir, (j) 
Membuat laporan mengenai produk pada jurnal, bekerja dengan penerbit yang dapat melakukan distribusi secara komersial.

Uji validitas dilakukan dengan tujuan untuk mengetahui sejauh mana tes dapat mengukur dengan tepat aspek yang akan diukur. Berdasarkan hal ini maka uji validitas dari tes ini adalah dengan menggunakan uji justifikasi ahli, dimana instrumen yang telah disusun dikonsultasikan kepada para ahli (pakar), yaitu pelatih tolak peluru, ahli pendidikan jasmani, dan guru pendidikan jasmani. Instrumen yang peneliti buat telah dijustifikasi oleh ahli dan dinyatakan valid sebagai instrumen untuk perekrutan atlet tolak peluru PPLM Putra Riau.

Validitas Konstrak

Validitas adalah suatu tingkatan yang mengukur karakteristik yang ada dalam fenomena didalam peneylidikan. Dalam penelitian ini, validitas yang digunakan adalah validitas konstrak yang merupakan tipe validitas yang mempertanyakan apakah konstrak atau karakteristik dapat diukur secara akurat oleh indicatorindikatornya. Validitas konstrak diukur dengan koefisien korelasiantara skor masing-masing indicator/item pertanyaan dengan skor totalnya faktor (X). Koefisien validitas diukur dari korelasi product moment atau korelasi Pearson yang dirumuskan sebagai berikut:

$$
r=\frac{\sum X Y-\frac{\left(\sum X\right)(\Sigma Y)}{n}}{\sqrt{\left[\sum X^{2}-\frac{\left(\sum X^{2}\right)}{n}\right]\left[\sum Y^{2}-\frac{\left(\Sigma Y^{2}\right)}{n}\right]}}
$$

Keterangan:

rxy = Koefisien korelasi suatu butir/item instrument

$\mathrm{N}=$ Jumlah subyek

$\mathrm{X}=$ Skor suatu butir/item

$Y=$ Skor total (Arikunto, 2005:72). 
Dalam menentukan tinggi rendahnya instrumen dipergunakan klasifikasi sebagai berikut.

\section{Tabel 1.}

\section{Kriteria Pengujian Reliabilitas}

\begin{tabular}{|c|c|}
\hline Hasil Pengujian & Kriteria \\
\hline $0,00-0,199$ & Sangat Rendah \\
\hline $0,20-0,399$ & Rendah \\
\hline $0,40-0,599$ & Sedang \\
\hline $0,60-0,799$ & Tinggi \\
\hline $0,80-1,000$ & Sangat Tinggi \\
\hline
\end{tabular}

Harga $r$ hitung selanjutnya dibandingkan dengan harga $r$ tabel. Untuk kesalahan $5 \%$ dua pihak dan $\mathrm{dk}=\mathrm{n}$. Ketentuan jika $r$ hitung lebih besar dari $\mathrm{t}$ tabel, maka instrumen layak untuk digunakan, dan begitu pula sebaliknya.

\section{Penghitungan Reliabilitas}

Salah satu syarat agar hasil suatu alat ukur dapat dipercaya adalah alat ukur tersebut harus mempunyai reliabilitas yang memadai. Uji relibialitas dalam penelitian ini dilakukan dengan uji Alpha Croanbach. Rumus Alpha Cronbach sebagai berikut:

$$
\begin{aligned}
& r_{11}=\left[\frac{n}{n-1}\right]\left[1-\frac{\sum \sigma_{i}^{2}}{\sigma_{t}^{2}}\right] \\
& \text { Keterangan : } \\
& r_{11} \quad=\text { reliabilitas instrumen. } \\
& n \quad=\text { banyaknya butir pertanyaan atau banyaknya soal. } \\
& \sum \sigma_{i}{ }^{2}=\text { jumlah varians butir. } \\
& \sigma_{t}{ }^{2} \quad=\text { varians total. }{ }^{19}
\end{aligned}
$$

Jika nilai alpha $>0.7$ artinya reliabilitas mencukupi (sufficient reliability), sementara jika alpha $>0.8$ ini mensugestikan seluruh item reliable dan seluruh item instrument konsisten secara internal karena memiliki reliablitas yang kuat.

Ni Putu Nita Wijayanti, Penerapan Model Pembelajaran Kooperatif Tipe Talking Stick Dapat Meningkatkan Hasil Belajar IPS Siswa Kelas Vb SDIT Insan Utama Pekanbaru 


\section{HASIL PENELITIAN}

\section{Uji Validitas}

Berdasarkan hasil pengukuran pengembangan instrument tolak peluru atlet putra maka dapat terlihat hasil analisis data korelasi product moment pada tabel dibawah ini:

Tabel 2.

Hasil analisis korelasi product moment masing-masing instrument tes

\begin{tabular}{|l|l|l|l|}
\hline No & Nama Instrumen & Nilai $r$ & Interpretasi \\
\hline 1 & Berat badan & 0.90 & Sangat tinggi \\
\hline 2 & Tinggi Badan & 0.97 & Sangat tinggi \\
\hline 3 & Rentang lengan & 0.72 & Tinggi \\
\hline 4 & Push up & 0.82 & Sangat tinggi \\
\hline 5 & Vertical jump & 0.78 & Tinggi \\
\hline 6 & Stork stance & 0.78 & Tinggi \\
\hline 7 & Speed 20 m & 0.75 & Tinggi \\
\hline 8 & Two hand medicine ball put & 0.77 & Tinggi \\
\hline 9 & Shuttle run & 0.60 & Tinggi \\
\hline 10 & Sit and reach & 0.63 & Tinggi \\
\hline 11 & Standing & 0.99 & Sangat tinggi \\
\hline
\end{tabular}

Dari tabel diatas dapat diuraikan item pengembangan instrument yang memiliki kriteria sangat tinggi berjumlah 4 item (36.36\%) yaitu berat badan, tinggi badan, push up, dan standing, sedangkan 7 item tes lainnya memiliki nilai korelasi product moment dengan kriteria tinggi sebanyak $63.36 \%$. 


\section{Uji Reliabilitas}

Uji relibialitas dalam penelitian ini dilakukan dengan uji Alpha Croanbach. Rumus Alpha Cronbach sebagai berikut:

$$
\begin{aligned}
& r_{11}=\left[\frac{n}{n-1}\right]\left[1-\frac{\sum \sigma_{i}^{2}}{\sigma_{t}^{2}}\right] \\
& \text { Keterangan : } \\
& r_{11} \quad=\text { reliabilitas instrumen. } \\
& n \quad=\text { banyaknya butir pertanyaan atau banyaknya soal. } \\
& \sum \sigma_{i}{ }^{2}=\text { jumlah varians butir. } \\
& \sigma_{t}{ }^{2} \quad=\text { varians total. }{ }^{19}
\end{aligned}
$$

Hasil pengujian ${ }_{r 11}=0.72$ ini artinya reliabilitas pengembangan yang peneliti buat mencukupi (sufficient reliability).

\section{Pembahasan Produk}

Produk yang dikembangkan ini bertujuan untuk membantu proses rekruitmen atlet khususnya cabang olahraga atletik nomor tolak peluru dengan pendekatan science. Dalam pengembangan instrumennya, peneliti mencari referensi komponen-komponen apa saja yang dibutuhkan dalam pencapaian prestasi, diantaranya aspek fisik, teknik, taktik dan mental. Tolak peluru merupakan salah satu nomor lempar, dimana menurut Dragan (1979) dalam Siswantoyo (2009: 63) mengidentifikasi unsur/kriteria yang dibutuhkan antara lain tinggi badan dan berotot, anaerobic tinggi, power, ukuran biacromial sebaiknya tinggi, waktu reaksi, konsentrasi. untuk menolak diperlukan tenaga yang besar, ini berarti sang atlit yang berpostur tinggi dan besar akan mempunyai peluang lebih besar untuk menjadi juara. Disamping kekuatan juga terdapat unsur lain yaitu kemampuan unsur ketangkasan, ketepatan waktu dan kecepatan melempar (Giri Wiarto, 2013: 57).

Untuk memperoleh tolakan yang jauh, dapat melakukan latihan beban secara kontinyu dan dengan intensitas latihan yang tepat. Komponen kondisi fisik 
yang dominan dibutuhkan pada nomor tolak peluru antara lain: kekuatan, daya ledak, kecepatan, kelentukan, kelincahan dan keseimbangan (jurnalristanso.blogspot.com, 2014). Prestasi tolak peluru ditentukan oleh tiga faktor yaitu: ketinggian saat melepaskan, kecepatan saat melepaskan, dan sudut yang dibentuk saat melepaskan peluru. Untuk memiliki ketinggian saat melepaskan peluru diperlukan tinggi badan yang lebih, karena dengan memiliki ketinggian saat melepaskan peluru diperlukan tinggi badan yang lebih tinggi maka akan mempunyai ketinggian saat melepaskan peluru lebih tinggi. Untuk menghasilkan kecepatan saat melepaskan dibutuhkan tenaga yang besar yang secara normal apabila seseorang memiliki badan yang lebih besar akan memiliki tenaga yang lebih besar sehingga untuk menghasilkan kecepatan saat melepaskan peluru lebih cepat, dan sudut saat lepas sesuai dengan rumus kecepatan saat mengudara sangat besar (Iman Imanudin, Jurnal Upi, Vol. 3, 2011).

Peneliti kemudian menggabungkan dan merancang menggabungkannya dalam sebuah draft pengembangan isntrumen tolak peluru dan melakukan revisi dulu kepada kelompok ahli yang terdiri dari pelatih atletik, dosen dan guru olahraga yang berkompeten. Proses revisi adalah poses memperbaiki, mengurangi maupun menambahkan instrument berdasarkan masukan-masukan yang ada. Tahapan setelah revisi adalah adanya ujicoba untuk melihat validitas pengembangan instrument yang dibuat.

\section{Keterbatasan Penelitian}

Dalam penelitian ini telah diupayakan secara maksimal sesuai dengan kemampuan dari peneliti, namun dalam penelitian ini masih terdapat beberapa keterbatasan yang harus diakui dan dikemukakan sebagai bahan pertimbangan dalam menggeneralisir hasil dari penelitian yang dicapai.

Adapun keterbatasan-keterbatasan tersebut antara lain sebagai berikut: (a) Fokus pengembangan ada pada aspek fisik dan teknik sebagai bagian terpenting yang akan dilatih setelah seorang atlet direkrut menjadi atlet PPLM, sehingga 
untuk instrument taktik dan mental uji validitasnya adalah uji validitas ahli saja, (b) Peminat dan atlet berbakat di nomor ini sangat minim sehingga perlu diadakan sosialisasi bersamaan dengan deseminasi produk.

\section{SIMPULAN}

Berdasarkan data yang diperoleh, dari hasil ujicoba kelompok kecil serta pembahasan hasil penelitian, dapat disimpulkan bahwa dihasilkan sebuah Pengembangan Instrumen Cabang Olahraga Atletik Nomor Tolak Peluru Gaya O'Brien pada Atlet Putra PPLM Provinsi Riau dengan nilai validitas item pengembangan instrument yang memiliki kriteria sangat tinggi berjumlah 4 item (36.36\%) yaitu berat badan, tinggi badan, push up, dan standing, sedangkan 7 item tes lainnya memiliki nilai korelasi product moment dengan kriteria tinggi sebanyak $63.36 \%$. Untuk hasil hasil pengujian reliabilitas nilai $r 11=0.72$ ini artinya reliabilitas pengembangan instrumen yang peneliti buat masuk pada katagori mencukupi (sufficient reliability).

\section{DAFTAR PUSTAKA}

Bahagia, Yoyo. (2003). Pembelajaran Atletik untuk Sekolah Luar Biasa. Bandung. Depdiknas.

Bompa. (1990). Theory and Methodology of Training, The Key To Atletik Performance. Dubege, Low: Kendall/Hunt Publishing Compani. Terjemah oleh Sarwono. Surabaya: Program Studi Ilmu Kesehatan Olahraga. Fakultas Pasca Sarjana Universitas Airlangga.

Bompa. (2000). Total Training for Young Champions. York University: Human Kinetics.

Deputi Sentra Keolahragaan, 2014. Petunjuk Pelaksanaan Tes dan Evaluasi Perkembangan Hasil Latihan PPLP/SKO/PPLM.

Febi Kurniawan \& Apta Mylsidayu, 2015. Ilmu Kepelatihan Dasar. Bandung: Alfabeta

Harsono. (1988). Coaching dan aspek-aspek Psikologi dalam Coaching. Jakarta. Tambak Kusuma.

Hay. James G.(1993). The Biomechanics of Sports Techniques. Prentice Hall Englewood Chiffs, New Jersey.

International Amateur Atlhetic Federation Coaches Education \& Certification System. (2000). Level I/II Sprint \& Hurdles Events Textbook. IAAF. 
Lutan, Rusli. Et al. (1992). Manusia dan Olahraga. Bandung. Diktat ITB dan FPOK/ IKIP Bandung.

Rosmalawati. (2000). Falsafah dan Metodologi Penelitian. Bandung. Diktat Universitas Jenderal Achmad Yani Cimahi.

Sadiman, Arif. S. 2003. Media Pendidikan Pengertian, Pengembangan, dan Pemanfaatannya. Jakarta : Pustekom Dikbud.

Siswantoyo, 2009. Pemanduan Bakat Olahraga. Yogyakarta: Universitas Negeri Yogyakarta

Sujana, (1992). Metode Statistika. Bandung. Tarsito

Sugiyono, 2008. Metode Penelitian Kuantitatif, Kualitatif dan R \& D. Bandung: Alfabeta

Wiarto, Giri. 2013. Atletik. Yogyakarta: Graha IImu. 